\title{
Assessment of the Attractiveness of Bangladesh As an ICT Offshoring Destination
}

\author{
Désirée van Gorp, Michiel Brandt, Henk Kievit \\ Nyenrode Business Universiteit, Breukelen, The Netherlands
}

\begin{abstract}
The authors established a theoretical framework for assessing the attractiveness of countries as information communication technology (ICT) offshoring destinations and identified Bangladesh as a case in point. The theoretical framework serves as the basis for their field research for which semi-structured interviews have been conducted with representatives of corporations, trade support initiatives, and public officials in both Bangladesh and the Netherlands. The authors assess the attractiveness of Bangladesh as the next ICT offshoring destination by making use of the Kotlarsky model. They conclude that despite some serious weak spots, Bangladesh is a favorable ICT offshoring destination. This is mainly due to its relatively high-skilled labor pool and high-quality services that can be offered at competitive prices and Bangladeshi ICT companies that can operate at relatively low costs. Furthermore, the government is supportive of building a flourishing ICT sector serving international markets and it should focus on mitigating regulatory risks, combating infringement of intellectual property rights, and creating infrastructure standards comparable with those of developed countries. At this point in time, the volume of ICT and hence the possibilities for upscaling ICT activities in Bangladesh remain limited. In positioning itself as an offshoring ICT location, Bangladesh could further promote its position as an ICT hub to India and Myanmar by focusing on impact sourcing and providing high-quality information-based services to domestic and international markets, thereby creating sustainable jobs that can generate step-function income improvement.
\end{abstract}

Keywords: Bangladesh offshore destination, information communication technology (ICT) offshoring and outsourcing, impact sourcing, assessment of offshoring locations, Kotlarsky model, comparative advantages

\section{Introduction}

In the academic literature, the role of the private sector in contributing to economic development and thereby enhancing the alleviation of poverty and contributing to social development has been discussed for decades (Hart, 1997; Nelson \& Prescott, 2003). A current basic assumption is that businesses from more developed countries, driven by economic opportunities, can contribute to the improvement of goods and services and the transfer of technical knowledge, innovation, and technology in developing countries. Increasing sustainable trade and value chain development have a positive effect on economic development.

Désirée van Gorp, Ph.D., professor of International Business Strategy at Nyenrode Business Universiteit, Breukelen, The Netherlands; visiting professor at Renmin University in China.

Michiel Brandt, a Ph.D. Candidate at the Center for Sustainability at Nyenrode Business University, Breukelen, The Netherlands.

Henk Kievit, Ph.D., Director of the Center for Entrepreneurship \& Stewardship at Nyenrode Business University, Breukelen, The Netherlands.

Correspondence concerning this article should be addressed to Désirée van Gorp, P.O. Box 130-3620 AC, Straatweg 25-3621 BG, Breukelen, The Netherlands. E-mail: d.vgorp@nyenrode.nl; m.brandt@nyenrode.nl. 
Economic growth driven by international business helps to reduce poverty by increasing employment and real incomes of the poor and on its turn enhances social development (Kolk, Rivera-Santos, \& Rufin, 2014).

A common manner of doing international business is relocating (parts of) activities to other countries, i.e., offshoring (Van Gorp, 2010). Until the 1990s, offshoring mostly involved physical goods. Since then, it, however, has taken a turn in that services have increasingly been relocated to other countries (Jagersma \& Van Gorp, 2006). This could be explained among others by technological progress resulting in costs of trading services internationally being significantly reduced (Freund \& Weinhold, 2002; Head, Mayer, \& Ries, 2009). According to Van Gorp (2010), the provision of service inputs from a foreign supplier is relocated abroad for many different reasons, such as the availability of talent and market entrance, whereby costs remain an important driver for offshoring. Low costs are found in developing countries and are for example related to the level of labor costs often being significantly lower than that in more developed countries (Prahalad \& Hammond, 2002).

According to Bigsten, Durevalla, and Munshic (2012), the offshoring of services can provide benefits for both sending as well as receiving countries. Companies in high-wage developed countries can, for example, create a comparative advantage by specializing in complex tasks while relocating some of their more routine tasks to low-wage developing countries. Meanwhile, jobs are created and revenue is generated at the offshoring destination as services are exported (Bigsten et al., 2012). Offshoring induces positive effects on innovation for firms in emerging economies.

Currently, over 125 developing countries aim to position themselves in the offshoring arena in order to attract foreign direct investments and expand economic activities (Kotlarsky, Levina, \& Kuraksina, 2013). Bangladesh, inspired by the successes of other South Asian countries, such as India, is one of the countries trying to find its niche market in the field of providing information communication technology (ICT) services to global markets. In its efforts to become a location for ICT services, Bangladesh is in competition with countries such as Vietnam, the Philippines, and Sri Lanka. Based on the quality of services and the costs associated with these services, the prospects of Bangladesh as a leading IT offshoring destination are promising (Kanti Bose, Uddin, \& Huda, 2013). Several high-profile consultancy firms have identified Bangladesh as an offshoring destination, for example, Bangladesh has been placed on its list of Top 30 Countries for Offshore Services, and Kearney (2014) ranked Bangladesh 26th on its Global Services Location Index. In 2012, the consultancy firm KPMG published a report in which it describes Bangladesh as an emerging destination for information technology/information technology-enabled services (IT/ITES) outsourcing.

This article reflects the outcome of a study in which the authors assessed the attractiveness of Bangladesh as an ICT offshoring location. Section 2 of this article describes the theoretical framework based on collected archival data. Section 3 presents the research methodology and the data used. In section 4 - the discussion section, the attractiveness of Bangladesh as an ICT offshoring destination is assessed, while the authors have synthesized the research data to the different factors of the Kotlarsky model. Section 5 concludes this paper: analyzes the main outcomes of the research and gives recommendations for policy makers in Bangladesh on how to upscale the market of ICT services, thereby enhancing the competitive position of Bangladesh in the global ICT market.

\section{Theoretical Framework}

The concept of ICT offshoring is not new. India, for example, has exported software and ICT services 
since the 1980s (Parthasarathy, 2013). Additionally, countries such as the Philippines, Malaysia, Romania, Poland, and Kenya have managed to establish flourishing ICT industries. ICT in this regard basically includes any type of software and software-related activities, such as ITES, ICT applications, software products, and embedded software (Carmel \&Tjia, 2005). Over the last decade, the offshoring of business processes, ITES, and ICT-related services have increased significantly, due to the rise of global trade and capital mobility as well as technical and logistical improvements (Jagersma \& Van Gorp, 2006). Carmel and Tjia (2005) identified six economic, business, and technology forces that together created the phenomenon of "offshore IT outsourcing". In random order of importance, they mentioned the following factors: (i) globalization of trade in services, (ii) business-friendly climate, (iii) growth of the offshore labor pool, (iv) drop in telecommunication costs, (v) software commoditization, and (vi) wage differentials.

Kotlarsky et al. (2013) identified various countries and regions as potential offshore locations for ICT. To assess the attractiveness of an offshore destination, several models have been developed. One of them is introducedwhich defined six main factors useful in selecting an offshore location. In this model, the factors are the following: (i) cost; (ii) availability of skills; (iii) environment; (iv) market potential; (v) risk profile; and (vi) quality of infrastructure.

Kotlarsky et al. (2013) assessed the attractiveness of Russia as an IT offshoring destination. In order to do so, they defined a list of factors hereby building on the model and including a seventh factor namely cultural compatibility. The Kotlarsky model consists of seven factors based on 23 indicators. Every factor is compiled of a set of indicators. Table 1 below provides an overview of the factors and indicators as used by Kotlarsky et al. (2013) for their assessment. In section 4 of this article, these seven factors are applied to Bangladesh. The researchers have chosen the Kotlarsky model for the assessment as it is particularly comprehensive and tailored to the ICT sector.

Table 1

Kotlarsky Model

\begin{tabular}{|c|c|c|}
\hline Factor & Indicator & Description \\
\hline \multirow{3}{*}{ I. Cost } & Labor costs & Average wages for skilled workers and managers \\
\hline & Infrastructure costs & $\begin{array}{l}\text { Unit costs for telecommunication networks, internet access and power, } \\
\text { and office rent }\end{array}$ \\
\hline & Corporate taxes & Tax breaks, regulations, and other incentives for local investment \\
\hline \multirow{2}{*}{ II. Skills } & Skill pool & Size of the labor pool with required skills \\
\hline & Vendor landscape & Size of the local sector providing IT services and other business functions \\
\hline \multirow{4}{*}{ III. Environment } & Government support & $\begin{array}{l}\text { Policy on foreign investment, labor laws, bureaucratic and regulatory } \\
\text { burden, and level of corruption }\end{array}$ \\
\hline & Business environment & Compatibility with prevailing business culture and ethics \\
\hline & Living environment & Overall quality of life, prevalence of HIV, and serious crime per capita \\
\hline & Accessibility & Travel time, flight frequency, and time difference \\
\hline \multirow{2}{*}{ IV. Market Potential } & Attractiveness of local market & Current gross domestic product and its growth rate \\
\hline & Access to nearby markets & Adjacent region \\
\hline \multirow{5}{*}{ V. Risk Profile } & Security risks & $\begin{array}{l}\text { Risks to personal security and property-related issues, such as fraud, } \\
\text { crime, and terrorism }\end{array}$ \\
\hline & Disruptive events & Risk of labor uprising, political unrest, and natural disasters \\
\hline & Regulatory risks & Stability, fairness, and efficiency of the legal framework \\
\hline & Macroeconomic risks & cost inflation, currency fluctuation, and capital freedom \\
\hline & Intellectual property & Strength of data and IP protection regime \\
\hline
\end{tabular}


Table 1 continued

\begin{tabular}{|l|l|l|}
\hline Factor & Indicator & Description \\
\hline \multirow{4}{*}{$\begin{array}{l}\text { VI. Quality of } \\
\text { Infrastructure }\end{array}$} & Telecommunication \& IT & Network downtime, speed of service restoration and connectivity \\
\cline { 2 - 3 } & Real estate & Availability and quality of real estate \\
\cline { 2 - 3 } & Transportation & Scale and quality of road and rail networks \\
\cline { 2 - 3 } $\begin{array}{l}\text { VII. Cultural } \\
\text { Compatibility }\end{array}$ & $\begin{array}{l}\text { Key characteristics of national } \\
\text { culture }\end{array}$ & Similarities to and differences from the cultures of the target markets \\
\cline { 2 - 3 } & Business culture & $\begin{array}{l}\text { Expectations and behaviors in the workplace and employer-employee } \\
\text { relations }\end{array}$ \\
\hline
\end{tabular}

\section{Methodology and Data}

Qualitative methods are used to assess the attractiveness of Bangladesh as an ICT offshoring destination. The research is based on a literature review on ICT offshoring to Bangladesh in order to define the theoretical framework of the study. A series of semi-structured interviews is conducted to learn more about the offerings of and the opportunities in the Bangladeshi ICT market. For these interviews, a checklist was used. In total, 20 professionals representing various types of organizations have been interviewed. Table 2 below gives specific information on the backgrounds of the interviewees. The interviews took between 30 and 60 minutes. Some of the interviews have been conducted by telephone and others have been taking place face-to-face.

Table 2

Overview of Background Interviewees

\begin{tabular}{|l|l|}
\hline No. of Interviewees & Affiliation \\
\hline 6 & Bangladeshi ICT services-exporting companies \\
\hline 3 & Bangladeshi public-sector organizations \\
\hline 2 & Bangladeshi ICT sector organizations \\
\hline 3 & Dutch/International ICT companies (experienced in doing business in Bangladesh) \\
\hline 4 & Dutch/International Trade Support Initiatives with a focus on ICT \\
\hline 2 & Dutch ICT outsourcing experts \\
\hline
\end{tabular}

\section{Discussion the Attractiveness of Bangladesh As an (ICT) Offshoring Destination}

The authors applied the Kotlarsky model to Bangladesh, hereby using the findings of the literature review and the semi-structured interviews. The research findings are reflected in the "conclusions" in section 5, which includes recommendations for policy makers on how to leverage on the attractiveness of Bangladesh as an ICT offshoring destination in order to accelerate the country's economic as well as social development. In the section below, the seven factors of the Kotlarsky model are discussed in more detail.

\section{Cost Factor}

An important driver for companies to offshore activities is reducing costs (Van Gorp, 2010). In the Kotlarsky model, the cost factor reflects three indicators, namely, (i) labor costs, (ii) infrastructure costs, and (iii) corporate taxes.

Labor costs. The ICT work force in Bangladesh is available for lower costs than labor with similar ICT skill sets in other ICT offshoring countries (KPMG, 2012). A KPMG report (2012) shows that the entry-level wages of Bangladeshi ICT workers are over 50\% lower compared to other countries in the region, such as India, Sri Lanka, and Vietnam. The difference with Eastern European offshoring destinations is even bigger. 
Bangladesh is $75 \%$ to $80 \%$ cheaper than ICT offshoring destinations such as Poland, the Czech Republic, and Hungary.

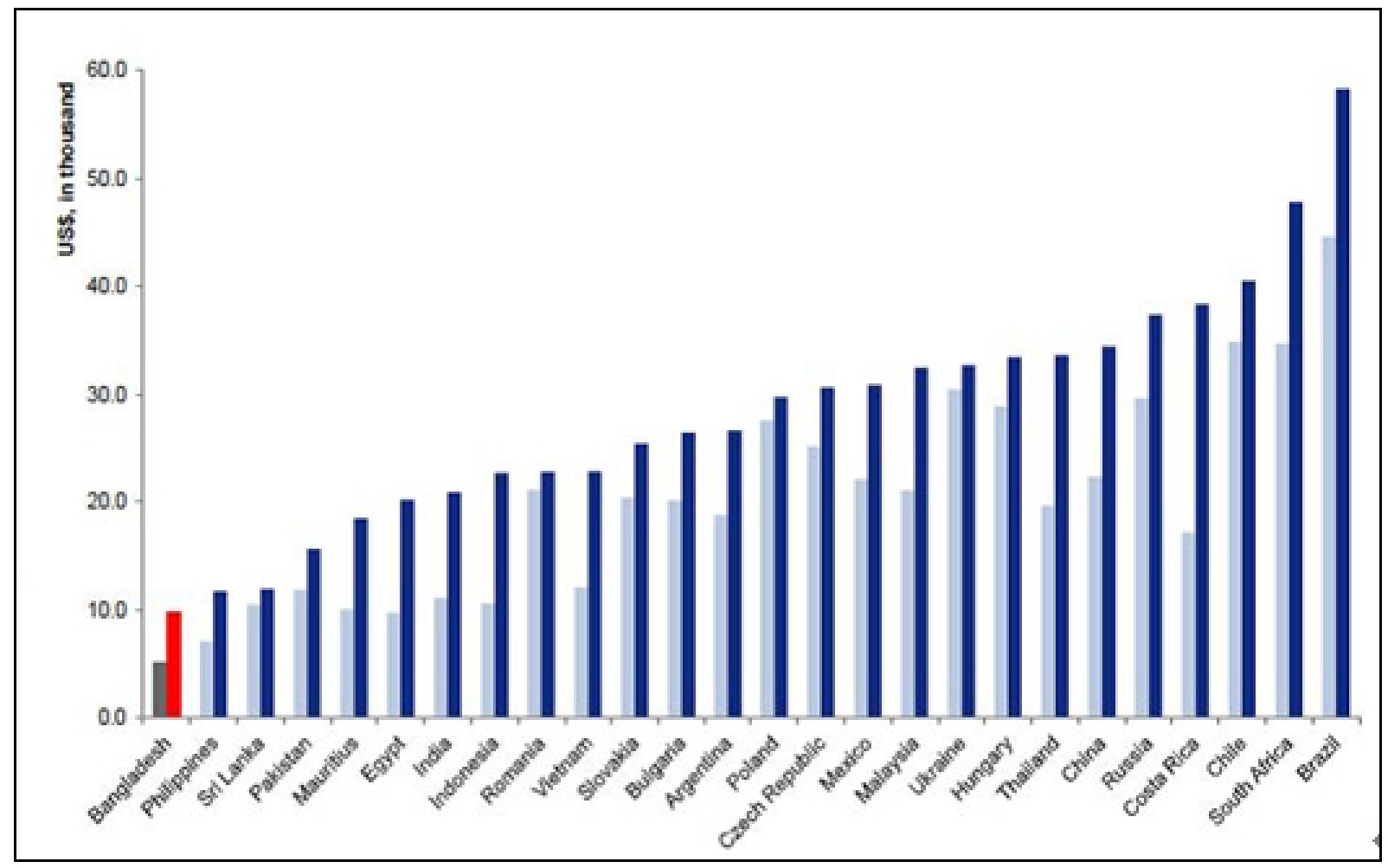

Figure 1. Average salary costs of IT resources at entry level and at five years' experience. Source: KPMG (2012).

Infrastructure costs. According to Santora (2014), the rent for office spaces in Dhaka is similar to those in other ICT markets in the region. The same report indicates that other costs associated with office housing, such as costs of operation and connecting to utilities, are slightly lower in Dhaka than that in other outsourcing hubs in the region such as Manila, Colombo, and Bangalore.

Corporate tax. The investment climate in Bangladesh is favorable, because it has a liberal investment regime. Bilateral investment treaties for the promotion and protection of foreign investments tariff-free access to Bangladesh is provided for the European Union, Canada, Australia, and Japan by way of the country's generalized system of references. Furthermore, as an incentive to develop the ICT sector, the government of Bangladesh (GOB) has exempted all software and ITES companies in Bangladesh from corporate taxation. Additionally, the GOB aims to attract foreign investments as the country strives for export competitiveness by offering export-oriented industrial enclaves, export processing zones, with infrastructural facilities and logistical support for foreign investors (Netherlands Bangladesh Business Platform, 2014).

Looking at the cost factor, it can be concluded that Bangladesh is able to offer ICT services at competitive prices, especially due to the relatively low labor costs and the tax exemption for the ICT sector. This competitive edge is reflected in the Global Services Location Index identifying the characteristics of the global offshoring landscape based on the financial attractiveness, residents' skills and availability, and business environment of 51 countries (Kearney, 2014). In this index, out of the 51 countries, Bangladesh leads in terms of financial attractiveness. 


\section{Skills Factor}

In the Kotlarsky model, the skills factor consists of two indicators: (i) the size of the skill pool and (ii) the vendor landscape. The skill pool is defined as the size of the labor pool with the required ICT skills (Kotlarsky et al., 2013). These skills include technical and business knowledge, management skills, languages, and the abilities to learn new concepts and innovate. The vendor landscape gives characteristics of the local sector providing ICT services.

Labor pool with required ICT skills. According to Heeks and Nicholson (2004), labor inputs are the most-cited single contributing factor to the software export successes of India, Russia, and Israel. In Bangladesh, a relatively young and growing population combined with increasing education creates a well-educated youth pool. A big part of this pool can read and write in English as it is a co-official language in Bangladesh. Nearly two-thirds of Bangladesh's total population is under the age of 34 (Central Intelligence Agency, 2014). In 2012, Bangladesh counted 80 public and private universities with more than 1.3 million new students enrolling every year (Bangladesh Ministry of Education, 2012). Annually, there are almost 15,000 university graduates in IT-related areas (Bangladesh Ministry of Finance, 2013). The Bangladeshi ICT workforce has well-developed hard skills, but it is believed to be less developed in terms of soft skills. According to some of the interviewees, many Bangladeshi ICT workers lack a certain level of creativity and the ability to strategically innovate. Others note that in Bangladesh, particular analytical and hard skill sets can be found that are currently lacking in more developed countries.

Vendor landscape. The vendor landscape of ICT providers in Bangladesh is dominated by small and medium-sized enterprises. According to industry statistics provided by the Bangladesh Association of Software and Information Services (BASIS), there are over 800 IT and ITES companies registered in the country (BASIS, n.d.). In 2012, BASIS carried out a survey among its member companies (around 600 members) showing that approximately $65 \%$ of the companies have 10 to 30 employees. It is estimated that not more than 20 companies have over 100 employees and just five companies in the Bangladeshi IT industry have over 200 employees. The total industry turnover is estimated around 250 million USD. The BASIS survey shows that among its member companies, over $75 \%$ is involved in customized application development and software maintenance. Almost half of them offer ITES to its customers. The specializations of the BASIS member companies are Customized Application Development (76\%), ITES (50\%), and Web Services (45\%).

Based on the insights given by the interviewees, it can be concluded that especially the labor factor in Bangladesh can be leveraged in becoming a mature ICT offshoring destination. The size and quality of the labor pool combined with the low costs associated with ICT labor give Bangladesh a unique selling point when offering ICT services.

\section{Environmental Factor}

This factor is described in the Kotlarsky model by three indicators, namely (i) government support, (ii) business environment, and (iii) living environment and accessibility.

Government support. According to Watson and Myers (2001), the presence of a national strategy for software exports is a vital part of software export success. In this regard, it is important that links between the industry and government help to ensure that the public policies are business-friendly (Tessler, Barr, \& Hanna, 2003). The GOB stresses that a vibrant ICT industry should be as multifarious as possible and result in the following: (i) become one of the largest employers of graduates; (ii) drive innovation in IT-based services; (iii) 
earn valuable foreign currency; and (iv) retain talent within the country. As such, the GOB formulated policies to increase exports of software development services and ITES as a form of business process outsourcing. In 2009, the national ICT policy was broadly reformulated across areas including education, science and technology, infrastructural development, employment generation, private-sector development, agriculture, health, and nutrition. The GOB included an e-governance vision, which should support the aim of delivering significant gains in terms of productivity and employment for both domestic as well as foreign investors. It also initiated digital Bangladesh, intending to create infrastructure for enhanced connectivity. In addition to policy development, the GOB is maintaining close relationships with industry associations. The support of the GOB is also illustrated by the above-mentioned corporate tax regimes applied to ICT companies. Furthermore, data of the International Finance Corporation and the World Bank (2014) show that Bangladesh holds the 130th position out of 189 economies. This ranking reflects the regulatory environment conducive to starting and operating a business. Bangladesh (130) ranks higher than India (134) but falls short of the South Asian regional average (121).

Business environment. Based on the experiences of the interviewees, the business community in Bangladesh is able to adapt easily to the business culture and ethics of Western customers. The Dutch interviewees commend the commitment of the Bangladesh ICT companies to meet the requirements of western companies and to make the outsourcing process successful for the customer. Furthermore, according to the interviewees, Bangladeshis are eager to learn and improve their skill sets in order to keep track of recent innovations and developments in the field of ICT.

Living environment. Despite many developments resulting in Bangladesh moving up the value chain as a country, it remains a poor overpopulated country with $31.5 \%$ of the population living below the poverty line (United Nations Development Programme [UNDP], 2014). According to the UNDP (2014), the average annual income per capita in Bangladesh is 848 USD. On the 2012 UNDP human development index, Bangladesh is ranked on place 148 (out of 186 countries). US-based human resource services consultancy firm Mercer yearly publishes a Location Evaluation and Quality of Living Report. In this report, living standards of 223 cities worldwide are assessed based on 39 factors in 10 different categories like political and social environment, housing, and schools and education. In the 2014 edition, Dhaka is ranked on position 208 giving the city the controversial second-lowest position in Asia, leaving only Dushanbe in Tajikistan behind (Mercer, 2014).

Accessibility. Based on input provided by the interviewees experienced with ICT offshoring to Bangladesh, the success of offshoring is partly determined by the relationship that is built with the supplier. In order to build this relationship, it is important that both parties have face-to-face meetings. Dhaka, being the capital of Bangladesh, is connected to the world as various international airlines like British Airways, Emirates, Thai Airways, and Singapore Airlines have regular flights operating to Dhaka's Shah Jalal International Airport. Obviously, Bangladesh is located in a different time zone (GMT +6) than other main ICT export destinations. According to the industry association BASIS, the top five export destinations for the Bangladeshi ICT sector are the United States, the United Kingdom, Canada, Australia, and Denmark. Bangladeshi service providers in the field of ITES, however, often adapt to the office hours of their western clients to serve international markets. Furthermore, due to time differences, a 24-hour development cycle could be leveraged. This may be a competitive edge of Bangladesh vis-à-vis other offshore destinations such as Sri Lanka, India, and the Philippines that are also in different time zones from their western customers. 
The indicators describing the environmental factor tell us that Bangladesh is a promising ICT offshoring location based on the positive business environment created by the eagerness of the Bangladeshi ICT work force to successfully serve western clients and the supportive character of the GOB. However, the quality of the living environment in Dhaka is perceived as low, which makes it a relatively unattractive city for expats. This factor might be relevant for companies considering ICT offshoring by way of foreign direct investments but will not necessarily hamper offshoring by taking a third party on board.

\section{Market Potential Factor}

The factor of market potential to assess the attractiveness of an offshore location has been introduced. It is based on (i) the local market and (ii) the access to nearby markets.

Attractiveness of the local market. The economy of Bangladesh is growing, expanding by $6.0 \%$ in 2013 (World Bank, 2014). The average growth rate of Bangladeshi GDP between 1994 and 2013 was 5.6\%, despite many obstacles, including political instability, corruption, relatively weak infrastructure, slow implementation of economic reforms, and insufficient power supply (Central Intelligence Agency, 2014). The opportunities in Bangladesh have been acknowledged by several global ICT companies, for example, the Korean technology firm Samsung has opened a high-end Research and Development (R\&D) center in Bangladesh employing over 250 engineers. VizRT, a Norwegian company that creates content production tools for the digital media industry, is investing in Bangladesh following acquisitions of ICT production companies in the country. Other global IT companies (e.g., AMD, LG, and IBM) are currently in the process of setting up back-office R\&D or support centers in Bangladesh (BASIS, n.d.). According to estimates of the industry association BASIS, $1 \%$ of Bangladesh's total GDP will come from the software and IT services sector within the next five years. By that time, over 150,000 software and IT professionals will be working in the Bangladeshi IT industry (BASIS, n.d.).

Access to nearby markets. There seems to be a window of opportunity for companies outsourcing ICT services to use Bangladesh as a hub to access its neighboring countries Myanmar and India. Myanmar, for example, is currently one of the least connected places in the world, with an internet penetration at approximately one percent. Only a small number of people know how to use computers and smartphones in this neighboring country. According to the Asian Development Bank (2012), telecommunications, including mobile telephony, are in urgent need of investment.

Regarding the market potential factor, it can be concluded that Bangladesh is an attractive ICT outsourcing destination. Especially in the field of R\&D, there are good opportunities. Taking into account that offshoring has positive effects on innovation in receiving countries, an untapped competitive advantage could be found in Bangladesh, because suppliers may be able to offer innovative software solutions and ICT products to Western customers and can serve as an ICT offshoring hub to neighboring countries, such as India and Myanmar.

\section{Risk Profile Factor}

In the Kotlarsky model, the risk profile factor includes the following five indicators: (i) disruptive events, (ii) security, (iii) regulatory risks, (iv) macroeconomic risks, and (v) intellectual property risks.

Disruptive events. Next to poverty, Bangladesh suffers from frequent natural disasters, such as floods, monsoons, cyclones, and droughts. The country is situated in a delta of the Ganges River and has to deal with melt water from the Himalayas. In the coastal areas, cyclones cause flooding regularly. At the same time, the political situation can become tense, especially during the period of election times. Hartals, mass protests involving a complete shutdown of workplaces, offices and public institutions, are common in Bangladesh. 
Some interviewees, however, indicated that hartals, political unrest, and natural disasters do not necessarily negatively impact business operations, because many Bangladeshi ICT companies provide their employees with laptops and at-home internet access to prevent reductions in productivity in case employees not being able to commute to the office.

Security. The Foreign and Commonwealth Office as a part of the government of the United Kingdom gives foreign travel advice to its nationals. According to the Foreign and Commonwealth Office (2014), political and other demonstrations, such as hartals, can quickly turn violent. During civil unrest and demonstrations, visitors should take great care. When it comes to crime, armed robbery, pick pocketing, and purse snatching can occur. Furthermore, there is a general terrorism treat. When asked, the interviewees stated that they generally feel safe when visiting Bangladesh.

Regulatory risks. Bangladesh is a member of the Multilateral Investment Guarantee Agency, an arm of the World Bank that has insured foreign investors against political risks, such as expropriation, inconvertibility, and war damage, since its establishment in 1988. Additionally, in Bangladesh, a policy framework for foreign investment based on the Foreign Private Investment (Promotion and Protection) Act 1980 is in place. This act provides for non-discriminatory treatment between foreign and local investment, protection of foreign investment from expropriation by the state, and ensured repatriation of proceeds from the sale of shares and profit. Unfortunately, the rule of law in Bangladesh is perceived to be low, because law enforcement is generally poor. Corruption remains an issue for Bangladesh. The Corruption Index 2013, published by Transparency International (2013), gives an indication of how corrupt public sectors are perceived to be. Bangladesh, at 136 on the list, ranks lower than Sri Lanka (91), India, and the Philippines, which share the 94th position on the list.

Macroeconomic risks. Bangladesh's GDP growth has been steady over the years with an average growth rate of $6.2 \%$ since 2005 (World Bank, 2014). A second macroeconomic risk is inflation. Data provided by the World Bank (2014) show that inflation, measured by consumer prices, has occurred in Bangladesh over the last few years. On average in the period from 2010 to 2013, the inflation rate has been $8.1 \%$ in Bangladesh. Compared to other countries in the region, this average inflation rate is slightly lower than in India (10.3\%) but higher than in countries such as Sri Lanka (6.8\%) and the Philippines (3.7\%). The interviewees indicated that they do not fear certain macroeconomic risks.

Intellectual property. In the world of ICT, some actors fear intellectual property issues in Bangladesh. To its credit, the country is a member of the World Intellectual Property Organization (WIPO) since 1985. Additionally, the legislative authorities in Bangladesh have enacted three main intellectual property laws by means of the Trademarks Act (Act No. XIX of 2009), the Patents and Designs Act (Act No. II of 1911), and the Copy Right Act (Act No. 28 of 2000, as amended in 2005). As law enforcement is perceived to be poor in Bangladesh, it could be questioned that to what extent the legal framework in place prevents intellectual property issues to arise. According to one interviewee, securing intellectual property rights can be an issue for ICT companies offshoring to Bangladesh, especially in the software development segment. A KMPG report refers to the negative image of the treatment of intellectual property rights due to numerous incidents of software piracy in Bangladesh (KPMG, 2012).

Based on the five indicators referred to above, it can be concluded that there are several risks associated with ICT offshoring to Bangladesh, especially regarding law enforcement, such as in intellectual property and disruptive events. According to the interviewees, these risks can be mitigated by selecting the right partners to relocate activities. 


\section{Quality of Infrastructure Factor}

This factor is compiled out of the following indicators: (i) telecommunication, (ii) real estate, (iii) transportation, and (iv) power.

Telecommunication and IT. According to the interviewees, the lack of reliable infrastructure remains a weak spot for Bangladesh. Issues regarding internet speed, bandwidth, and electricity are key problems that regularly affect daily operations. Since many of the companies are dedicated to software development, the damage caused by poor internet connectivity is limited, because it is of less importance for this type of business. The internet connection in Bangladesh has become more reliable since the landline to India was laid next to the submarine cable from Singapore (Netherlands Bangladesh Business Platform, 2014). In order to safeguard continuous connectivity, many Bangladeshi ICT companies use fallback lines for internet and telephone.

Real estate. The GOB is building a special high-technology and software technology park to facilitate the development of infrastructure and business environment needed by ICT companies serving international markets. The GOB has established the Bangladesh hi-tech park authority to operate this initiative.

Transportation. In particular, local transportation in Dhaka can be challenging. In the Dhaka area, most local people commute by bus, car, taxi, bone-shattering motorized three-wheelers (so-called CNGs), rickshaw, or motorbike. Due to the fast-growing number of cars and the limited road system in Dhaka, traffic jams are, however, almost unavoidable.

Power. Power outages and shortages are common in Bangladesh. According to the interviewees, most of the ICT companies operating from Bangladesh have in-house power generators to guarantee continuous access to power. Thus, business operations generally do not suffer from the weak power infrastructure in Bangladesh.

Bangladesh as a developing country has its issues with the continuous supply of power, connectivity and transportation. According to the interviewees, however, these issues are managed by Bangladeshi ICT companies offering services and products to international markets.

\section{Cultural Compatibility}

The factor of cultural compatibility is compiled from two indicators: (i) the characteristics of national culture and (ii) the business culture.

Characteristics of the national culture. In Bangladesh, approximately $90 \%$ of the population is Muslim, whereas $9 \%$ is Hindu. This makes Bangladesh a rather homogeneous nation. The nation is mainly built on Islamic values.

Business culture. In Bangladesh, office hours run from Sunday until Thursday, because Friday is the regular day of prayers for Muslims. Bangladeshis enjoy their weekends on Fridays and Saturdays. Based on the interviews, authors can conclude that most companies offering ITES services adapt to the demands of their customers and work on Fridays if required by the customer. The business culture in Bangladesh can be characterized as formal. According to the interviewees, people in Bangladesh normally work hard to perform the job assigned to them as well as possible.

The interviewees are generally positive and have not experienced any significant barriers, due to cultural differences when doing business in Bangladesh.

\section{Conclusions}

Based on the assessment of the Kotlarsky model, it can be concluded that Bangladesh is a favorable ICT 
offshoring destination, because Bangladeshi ICT companies can operate at relatively low costs, due to tax advantages and low labor and infrastructure costs. Bangladesh is perceived to have a major advantage over other ICT offshoring destinations in developing countries especially due to its relatively high-skilled labor pool, high-quality services that can be offered at competitive prices. Furthermore, the GOB is supportive of building a flourishing ICT sector serving international markets.

Law enforcement, infrastructure, and disruptive events are still perceived as weak spots in Bangladesh. It would be beneficial to the sector, if the GOB focuses on changing local circumstances by mitigating regulatory risks, combating infringement of intellectual property rights, and creating infrastructure standards comparable with those of developed countries. Establishing additional internet hubs and broadband networks in remote areas is something that could be considered. Limited internet access for companies and freelancers outside of urban areas slow down further industry development and formation of additional small ICT clusters.

As the ICT sector in Bangladesh offers high-quality services and goods at competitive prices, it potentially is an attractive ICT offshore destination for many Western companies. At this point in time, the volume of ICT and hence the possibilities for upscaling ICT activities in Bangladesh remain limited. Future research is needed to understand why this is the case. In promoting Bangladesh as an ICT offshore destination, a more explicit link with sustainable development could be made. Emphasizing "impact sourcing", a concept introduced by Heeks (2013), could be in this context be of added value, because in the Western world, many companies have social responsibility and sustainable development embedded into their business strategies. Impact sourcing is defined as employing people at the base of the pyramid as principle workers in outsourcing to provide high-quality and information-based services to domestic and international markets, thereby creating sustainable jobs that can generate step-function income improvement (Heeks, 2013).

In positioning itself as an offshoring ICT location, Bangladesh could further promote its position as an ICT hub to India and Myanmar. A thorough analysis of the comparative advantages among these three countries would help to further strengthen this positioning.

\section{References}

Asian Development Bank. (2012). Myanmar in transition, opportunities and challenges. Retrieved from http://www.adb.org/sites/default/files/publication/29942/myanmar-transition.pdf

Bangladesh Association of Software and Information Services. (n.d.). Bangladesh software and IT service industry-Recent trends \& dynamics. $\quad$ Retrieved from http://www.basis.org.bd/resource/About_BASIS_\&_Bangladesh_Software_and_ITS\%20_Industry.pdf

Bangladesh Ministry of Education. (2012). Education statistics. Retrieved from http://www.moedu.gov.bd/index.php?option=com_content\&task=view\&id=300\&Itemid=301

Bangladesh Ministry of Finance. (2013). Towards a digital Bangladesh. Retrieved from http://mof.gov.bd/en/budget/ebook/digital_journey.pdf

Bigsten, A., Durevalla, B., \& Munshic, F. (2012). Offshoring and occupational wages: Some empirical evidence. The Journal of International Trade \& Economic Development, 21, 253-269.

Carmel, E., \& Tjia, P. (2005). Offshoring information technology-Sourcing and outsourcing to a global workforce. Cambridge: Cambridge University Press.

Central Intelligence Agency. (2014). The world fact book, about Bangladesh. Retrieved from https://www.cia.gov/library/publications/the-world-factbook/geos/bg.html

Foreign and Commonwealth Office. (2014). Foreign travel advise-Bangladesh. Retrieved from https://www.gov.uk/foreign-travel-advice/bangladesh/safety-and-security

Freund, C., \& Weinhold, D. (2002). The internet and international trade in services. American Economic Review Papers and Proceedings, 92, 236-240. 
Hart, S. (1997). Beyond greening: Strategies for a sustainable world. Harvard Business Review, 75(1), 66-76.

Head, K., Mayer, T., \& Ries, T. (2009). How remote is the offshoring threat? European Economic Review, 53, 429-444.

Heeks, R. (2013). Information technology impact sourcing. Communications of the ACM, 56(12), 22-25.

Heeks, R., \& Nicholson, R. (2004). Software export success factors in follower nations. Competition \& Change, 8(3), $267-303$.

International Finance Corporation., \& the World Bank. (2014). Doing business, data Bangladesh. Retrieved from $\mathrm{http}: / / w w w . d o i n g b u s i n e s s . o r g / d a t a / e x p l o r e e c o n o m i e s / b a n g l a d e s h / \#$ starting-a-business

Jagersma, P. K., \& Van Gorp, D. (2006). Redefining the paradigm of global competition: Offshoring of service firms. Business Strategy Series, 8, 35-42.

Kanti Bose, T., Uddin, R., \& Huda, N., (2013). Prospects of Bangladesh as a leading outsourcing destination in IT sector. International Journal of Managing Value and Supply Chains, 4, 1-16.

Kearney, A. T. (2014). Global services location index. Retrieved from http://www.atkearney.com/documents/10192/5082922/A+Wealth+of+Choices.pdf/61c80111-41b2-4411-ad1e-db4a3d6d5f0d

Kolk, A., Rivera-Santos, M., \& Rufin, C. (2014). Reviewing a decade of research on the base/bottom of the pyramid concept, business, and society. Business \& Society, 53(3), 338-477.

Kotlarsky, J., Levina, N., \& Kuraksina, E. (2013). Evaluation of Russia's attractiveness as an IT offshoring destination (The Oxford Handbook of Offshoring and Global Employment).

KPMG. (2012). Bangladesh beckons: An emerging destination for IT/ITES outsourcing. Retrieved from https://www.kpmg.com/BD/en/Documents/UNITC\%20KPMG\%20Whitepaper.pdf

Mercer. (2014). Location evaluation and quality-of-living reports. Retrieved from http://www.imercer.com/products/2014/quality-of-living.aspx

Nelson, J., \& Prescott, D. (2003). Business and the Millenium development goals: A framework for action. Proceedings from The Prince of Wales International Business Forum.

Netherlands Bangladesh Business Platform. (2014). ICT sector study Bangladesh bridging the gap between Dutch and $\begin{array}{llll}\text { Bangladeshi } & \text { ICT } & \text { Rectors. } & \text { Retrieved }\end{array}$ http://www.nbbp.org/_downloads/Nyenrode_Report_Exploring_the_ICT_sector_in_Bangladesh.pdf

Parthasarathy, B. (2013). The changing character of Indian offshore ICT services provision (The Oxford Handbook of Offshoring and Global Employment).

Prahalad, C. K., \& Hammond, A. (2002). Serving the world's poor, profitably. Harvard Business Review, 80(9), 48-57.

Santora, J. (2014). Emerging and Frontier markets, assessing risk and opportunity. Retrieved from: http://www.cushmanwakefield.com/ /media/global-reports/Emerging\%20Market\%20Risks\%202014.pdf

Tessler, S., Barr, A., \& Hanna, N. (2003). National software industry development: Considerations for government planners. Electronic Journal of Information Systems in Developing Countries, 13, 1-17.

Transparency International. (2013). The corruption index 2013. Retrieved from http://www.transparency.org/cpi2013

United Nations Development Programme. (2014). Bangladesh country information. Retrieved from http://www.bd.undp.org/content/bangladesh/en/home/countryinfo/

Van Gorp, D. (2010). Offshoring in the service sector: An empirical investigation on the offshoring behavior of service firms and its influence on their foreign entry mode choice. Saarbrücken: LAP Lambert Academic Publishing.

Watson, R., \& Myers, M. D. (2001). IT industry success in small countries: The cases of Finland and New Zealand. Journal of Global Information Management, 9, 4 -14.

World Bank. (2014). GDP growth data bank. Retrieved from http://data.worldbank.org/indicator/NY.GDP.MKTP.KD.ZG 